\title{
The effects of air pollution on vitamin D status in healthy women: A cross sectional study
}

Farhad Hosseinpanah ${ }^{1 *}$, Sima Hashemi pour ${ }^{2}$, Motahare Heibatollahi ${ }^{1}$, Nilufar Moghbel ${ }^{3}$, Saeed Asefzade ${ }^{4}$, Fereidoun $\mathrm{Azizi}^{3}$

\begin{abstract}
Background: Inadequate radiation or insufficient cutaneous absorption of UVB is one of the cardinal causes of vitamin $D$ deficiency. The aim of this study is to determine whether air pollution and low ground level of ultraviolet B light (UVB; 290-315) can deteriorate the body vitamin D status in healthy women.

Methods: In this cross sectional study 200, free-living, housewives, aged between 20 to 55 years, from Tehran (high polluted area) and Ghazvin (low polluted area) were included. The Tehranian women were selected randomly from participants of the Tehran Lipid and Glucose Study (TLGS) and the Ghazvinian females from patients who came to public health centers. Participants were excluded for disease and drugs which affect vitamin D status and also if they were pregnant or breast feeding. We measured the ground level of UVB using a Haze meter as a surrogate of air pollution. In order to calculate the adjusted mean difference of 25-OH-D, ANCOVA analysis was used. Moreover, Binary logistic regression model was developed to determine the odds of living in Tehran for having serum 25-OH-D less than $20 \mathrm{ng} / \mathrm{ml}$.

Results: The mean \pm SD of serum 25-OH-D was significantly higher in Ghazvinian women ((18 \pm 11 vs. $13 \pm 7)$, Pvalue < 001). The prevalence of 25-OH-D less than $10 \mathrm{ng} / \mathrm{ml}$, and 25-OH-D between 10 and $20 \mathrm{ng} / \mathrm{ml}$ were higher in Tehranian group (36\% and $54 \%$ vs. $31 \%$ and $32 \%$ in respectively). Secondary hyperparathyroidism was also significantly higher in Tehranian women (47\% vs. 32\%). In ANCOVA analysis, after adjustment, the mean of 25-OH-D in the Ghazvinian group was still statistically significantly higher than Tehranians (13 vs. $17 \mathrm{ng} / \mathrm{ml} \mathrm{P-value}=0.04)$. In addition, in binary logistic model, the odd of living in Tehran for having serum $25-\mathrm{OH}-\mathrm{D}$ less than $20 \mathrm{ng} / \mathrm{ml}$ was 5.22 (95\% confidence interval 2.2-12.2, P-value $<0.001$ ).
\end{abstract}

Conclusion: We found that living in a polluted area plays a significant independent role in vitamin $D$ deficiency and hence, residence can be one of the main reasons of vitamin $D$ status of the women.

\section{Background}

Skin synthesis of vitamin D, under the influence of UVB, includes about $90 \%$ of all the body's requisites. Meanwhile, dietary sources of vitamin D (e.g., fish liver oils, egg yolks, and vitamin D fortified foods) are only responsible for a small portion of body requirements. Hence, inadequate radiation or insufficient cutaneous absorption of UVB is one of the cardinal causes of vitamin D deficiency. Severe vitamin D deficiency is common amongst sunlight-deprived individuals [1]. The efficacy of cutaneous synthesis of vitamin D is

\footnotetext{
* Correspondence: fhospanah@endocrine.ac.ir

'Obesity Research Center, Research Institute for Endocrine Sciences, Shahid Beheshti University of Medical Sciences, P.O. Box 193-4763, Tehran, Iran Full list of author information is available at the end of the article
}

determined mainly by age, degree of skin pigmentation, and most importantly, by the extent of body attainable UVB [2-4] which depends largely on the percentage of UVB that reaches the earth surface and also by clothing styles i.e. determining the amount of unprotected skin exposure to available UVB [5]. The main factors influence the earth surface magnitude of UVB, are geographic latitude, season, time of day i.e. peak UV period 10:00-15:00 am, and the levels of atmospheric pollution [2,6-8].

Air pollution is one of the chief actors in determining the percentage of the ground level of UVB. The level of air pollution is inversely related to the extent of solar UVB that reaches earth surface, consequently, more pollutant areas, less UVB passage and as a result, lowers
C Biomed Central

(c) 2010 Hosseinpanah et al; licensee BioMed Central Ltd. This is an Open Access article distributed under the terms of the Creative Commons Attribution License (http://creativecommons.org/licenses/by/2.0), which permits unrestricted use, distribution, and reproduction in any medium, provided the original work is properly cited. 
vitamin D cutaneous synthesis. Nevertheless, not enough studies have evaluated the probable relation between cutaneous vitamin $\mathrm{D}$ synthesis and the ground level of UVB, as a function of air pollution. one study in India has found that high atmospheric pollution decreases the percentage of UVB which reaches the earth surface and children in more pollutant areas are at higher risk of vitamin D deficiency [9]. Another study in Belgian postmenopausal women also confirmed the positive correlation between air pollution and hypovitaminosis D [10].

In this study, we conducted a cross-sectional survey of healthy and relatively young women, (aged 20-55 years) recruited from general population, in two areas with different ground level of UVB, to determine the independent role of air pollution on vitamin $\mathrm{D}$ status.

\section{Methods}

This cross-sectional study was conducted in September 2007, on 200 women, to evaluate the role of air pollution on blood level of 25-OH-D, as the best indicator of vitamin $\mathrm{D}$ storage. Considering the degree of air pollution, we defined two separate zones, of approximately similar latitude; the east of Tehran, latitude $35 / 7117^{\circ} \mathrm{N}$, as a significantly polluted area, and Ghazvin city, latitude $36 / 2693^{\circ} \mathrm{N}$, a less polluted area. Ghazvin is located $165 \mathrm{~km}$ northwest of Tehran, in the Ghazvin Province, at an altitude of about 1800 meters above sea level, with a cold and dry climate due to its position south of the rugged Alborz range. This is while Tehran is the capital of Iran and Tehran Province, located 1139 meters above sea level with a a semi-arid, continental climate. We measured the ground levels of UVB by a Haze meter instrument, type UVB EC1 HANGER, on a completely sunny day, between 9 am and $12 \mathrm{pm}$, in 3 centers in district 13 of Tehran and 10 centers in Ghazvin. The unit of UVB measurements was watt per square meter $\left(\mathrm{W} / \mathrm{m}^{2}\right)$. The ground level of UVB was significantly higher in Ghazvin as compared with Tehran (mean (SE), $0.31(0.07)$ and $0.16(0.03) \mathrm{W} / \mathrm{m}^{2}$ respectively, $\mathrm{P}$-value $=$ 0.003).

All participants were selected using a randomized cluster sampling method; cases were the outpatient housewives, aged between 20 and 55 years. The Tehranian women were selected randomly from participants of the TLGS [11]. TLGS is a population based study, conducted to determine the prevalence of non-communicable diseases among Tehranian's urban population and to develop population-based measures to decrease the prevalence and prevent the rising trend of diabetes mellitus and dyslipidemia. Ghazvinian women selected from subjects who came to public health centers for problems other than those related to vitamin D status. Based on patients' information, those excluded from this study on the basis of medical histories, including known history of malabsorption and gastrointestinal surgeries, cirrhosis, infertility, diabetes mellitus, Cushing's disease, oligomenorrhea, malignancy, and chronic renal failure. Furthermore, participants that were under anti-epileptic, corticosteroid, levothyroxine, Isoniazid, and cholestyramin therapy and those that used vitamin D ampoules in the last 6 months and finally pregnant or breastfeeding women were excluded. Eventually based on inclusionexclusion criteria, we selected 100 women from Tehran and 100 women from Ghazvin. The project was explained to each participants and written informed consent was obtained at the time of enrollment on an institutionally approved protocol and consent form. The study protocol was approved by the research ethics committee of the Research Institute for Endocrine Sciences affiliated to Shahid Beheshti University, Tehran, Iran.

To take into account different parameters that may contribute to control of vitamin D status, two questionnaires were designed, one for nutritional evaluations (Food Frequency Questionnaires (FFQ) [12]) and other to assess degree of daily sun exposure. To assess the validity of FFQ, dietary data of 132 individuals were collected by means of 24-h dietary recall (24hDR), repeated twelve time; $24 \mathrm{hDR}$ interviews were performed every month for 12 months by the same trained dietitians according to a standard protocol. Usual dietary intake was assessed twice using a 168-item semi-quantitative FFQ (FFQ1 and FFQ2), all administered by the same trained dietitians for each participant fir assessing intrarater reliability. The first recall was completed one month after FFQ1 administration and the last recall was completed one month before administration of FFQ2. In women, energy-adjusted and deattenuated correlation coefficients mean nutrient intake in the $24 \mathrm{hDR}$ and FFQ were 0.33 and 0.43 for calcium and vitamin $D$, respectively; the age and energy adjusted interclass correlations for calcium and vitamin $\mathrm{D}$ were 0.56 and 0.71 respectively [12]. Nutritional data precisely collected, were analyzed by our nutritionists and the daily usage of $\mathrm{Ca}$, $\mathrm{Pi}$, vitamin $\mathrm{D}$, and protein were extracted. Because the Iranian food composition table (FCT) is incomplete (limited to only raw materials and few nutrients), each food and beverage was analyzed for nutrient intake using the US Department of Agriculture's (USDA) FCT $[13,14]$. We used the Iranian FCT only for food items like "kashk" which was not listed in USDA FCT. We did not have the possibilities to measure dietary phytate intake. The other questionnaire evaluated the degree of personal daily sun exposure. We inquired about their housing status (i.e. apartment or villa), time spent outdoor whether over or less than 3 days in a week, and the usage pattern of sunscreen (i.e. always or sometimes or never); each of the above questions was analyzed 
separately. In addition, to calculate the Body Mass Index (BMI), an important determinant of vitamin D status, the height and the weight of these women were also measured; weight was recorded, using a Seca 707 weighing machine (range, $0.1-150 \mathrm{~kg}$ ) with an accuracy of up to $100 \mathrm{~g}$, the machine being checked regularly for precision every 10 measurements. Height was measured without shoes using a tape stadiometer with a minimum measurement of $1 \mathrm{~mm}$. BMI was calculated by dividing weight (in kilograms) by height squared (in meters).

For determination of 25-OH-D, Parathyroid hormone (PTH), Calcium, Phosphorus and total Alkaline Phosphatase level (ALP), $10 \mathrm{ml}$ of venous blood was taken from antecubital vein of participants, between 8:00 am and 9:00 am after 12-14 h overnight fasting; all samples were centrifuged after collection and $15 \mathrm{~min}$ incubation at room temperature $\left(3000 \mathrm{rpm}, 15 \mathrm{~min}\right.$ at $\left.4^{\circ} \mathrm{C}\right)$. Sera 25-OH-D was measured using the Enzyme Immunoassay (EIA) method (25 OH VitD EIA kit, DRG, Marburg, Germany); the kit expected range $10-50 \mathrm{ng} / \mathrm{ml}$. The assay sensitivity was $5.6 \mathrm{nmol} / \mathrm{L}$, and intra-inter assay coefficient variation percents (CV \%) were 2.7 and 3.9 respectively. Sera PTH level was determined using an enzyme-linked immunosorbent assay (ELISA) method (hPTH ELISA kit, Biosource, Belgium); the kit expected range $16-64 \mathrm{pg} / \mathrm{ml}$. The assay sensitivity and the intrainter assay coefficients of variation were $2 \mathrm{pg} / \mathrm{ml}, 6.4 \%$ and $7.8 \%$ respectively. Calcium, Phosphate and total ALP levels were measured using photometric methods (Calcium CPC, Phosphorous UV and Alkaline Phosphatase DGKC Kit, Pars Azmoun Co., Tehran, Iran). The sensitivity of assays mentioned were $0.2 \mathrm{mg} / \mathrm{dl}, 0.7 \mathrm{mg} /$ $\mathrm{dl}$ and $3 \mathrm{U} / \mathrm{L}$ respectively. Intra and inter assay CV\% for calcium, phosphorous and total ALP of the samples were $1.4,2.7,1.9,3.1$, and $1.1,1.8$ respectively.

Statistical analyses were performed using SPSS version 16.0 software. The normality of distribution was checked for all variables by Kolmogorov-smirnov analysis. If required, skewed variables were logarithmically transformed to improve normality prior to analyses, if it was needed. Normally distributed continuous variables are reported as the mean \pm SD and not normally distributed continuous variables are reported as median and Interquartile (IQ) 25-75.

Student's t-test for unpaired data was used to compare groups and other than that the Mann-Whitney test was used. Correlation coefficients were calculated by Pearson's analysis. adjusted mean differences were calculated using ANCOVA. A binary logistic analysis was performed in all 200 subjects to determine the role of the city of residence per se, as an surrogate of air pollution, for having blood level of 25-OH-D less or more than 20 $\mathrm{ng} / \mathrm{ml}$ following adjustment of the confounders, i.e. age (years), BMI $\left(\mathrm{kg} / \mathrm{m}^{2}\right)$, dietary usage of $\mathrm{Ca}(\mathrm{mg})$, Pi $(\mathrm{mg})$, vitamin D (ug), and protein (gr), housing status (reference, villa), time spent outdoor (reference, $>3$ days in week), the pattern of sunscreen usage (reference, routine), and the city of living (reference, Ghazvin). Vitamin D deficiency, insufficiency, and normal cut offs considered were as $25-\mathrm{OH}-\mathrm{D}<10 \mathrm{ng} / \mathrm{ml}, 12$ to $<20 \mathrm{ng} / \mathrm{ml}$, and $\geq 20 \mathrm{ng} / \mathrm{ml}$, respectively [15]. P-values $<0.05$ were considered statistically significant.

\section{Result}

Two hundred housewives, aged 20 to 55 years, from Tehran and Ghazvin, participated in this study. Ninety four (47\%) were overweight and 38 (19\%) were obese. The age and BMI of these 2 groups were statistically different but their values were clinically comparable. There were no significant differences between the daily dietary intakes of $\mathrm{Ca}, \mathrm{Pi}$, vitamin $\mathrm{D}$, and protein of these groups. The sun exposure indices were higher in Ghazvinian participations (Table 1).

Table 2 shows the differences in biochemical parameters of Tehranian and Ghazvin participants. Median serum 25-OH-D was significantly higher in Ghazvin women (11 vs. $15.5 \mathrm{ng} / \mathrm{ml}, \mathrm{P}$-value < 001). The prevalence of vitamin $\mathrm{D}$ deficiency and insufficiency were higher in Tehranians (36\%, 54\% vs. 31\%, 32\%) (Fig 1). Secondary hyperparathyroidism was found in $32 \%$ of Ghazvin participants while, $47 \%$ of Tehranian women had secondary hyperparathyroidism. Median PTH was significantly lower in the Ghazvin group, compared to Tehranians (P-value < 001). Serum Ca was significantly higher in Ghazvinian women (P-value $=0.001)$. The serum ALP and Pi were similar in both groups.

Significant and negative correlation was observed between serum 25-OH-D and PTH (correlation coefficient $=-0.86$, P-value $<001)$, whereas there were no significant correlation between 25-OH-D, and other parameters. We did not find any association between each of the defined subgroups i.e. housing status (apartment or villa), time spent outdoor (more than 3 days or less that 3 days in a week), and the style of sunscreen usage (routine, never, occasional), and serum vitamin D.

In ANCOVA Analysis, the adjusted mean difference of 25-OH-D in Ghazvin and Tehranian participations was $4 \mathrm{ng} / \mathrm{ml}(13$ vs. $17 \mathrm{ng} / \mathrm{ml}$, P-value $=0.04)$.

In the binary logistic regression, serum 25-OH-D was significantly associated with the city of living. The odds ratio of living in Tehran and having serum 25-OH-D less than $20 \mathrm{ng} / \mathrm{ml}$ was 5.22 (95\% confidence interval 2.2-12.2, P-value < 0.001).

\section{Discussion}

This study, in healthy free-living women aged 20-55 years, demonstrates that city of residence and air pollution play significant independent roles in vitamin D 
Table 1 Characteristics of the participants.

\begin{tabular}{llll}
\hline & Tehran High pollution area & Ghazvin Low pollution area & Total \\
\hline Age $($ years) & $35(29-42)$ & $39(31-44)^{* * *}$ & $37(31-44)$ \\
\hline BMl $\left(\mathrm{kg} / \mathrm{m}^{2}\right)^{* *}$ & $28 \pm 5$ & $26 \pm 3^{* * *}$ & $27 \pm 4.6$ \\
\hline Daily dietary Calcium intake $(\mathrm{mg})^{* *}$ & $964 \pm 402$ & $880 \pm 343$ & $925 \pm 379$ \\
\hline Daily dietary Phosphor intake $(\mathrm{mg})^{* *}$ & $1255 \pm 491$ & $1113 \pm 430$ & $1184 \pm 424$ \\
\hline Daily dietary vitamin D intake $(\mathrm{ug})^{*}$ & $1.67(0.8-2.8)$ & $1.60(0.6-2.7)$ & $1.60(0.9-2.7)$ \\
\hline Daily dietary protein intake $(\mathrm{gr})^{* *}$ & $67 \pm 27$ & $62 \pm 35$ & $64 \pm 27$ \\
\hline Housing status\% *** & & & $120(60)$ \\
Apartment & $73(73)$ & $47(47)$ & $80(40)$ \\
Villa & $27(27)$ & $53(53)$ & $154(77)$ \\
\hline Time spent outdoor\% *** & & $85(85)$ & $46(23)$ \\
$>3$ days in week & $69(69)$ & $15(15)$ & \\
$<3$ days in week & $31(31)$ & & $53(26.5)$ \\
\hline Sun screen \% & & $20(20)$ & $91(45.5)$ \\
Routine & $33(33)$ & $50(50)$ & $56(28)$ \\
Never & $41(41)$ & $30(30)$ & $0.27 \pm 0.09$ \\
Occasion & $26(26)$ & $0.31 \pm 0.07)^{* * *}$ & \\
\hline UVB $(W / m$ 2) & $0.16 \pm 0.03$ & & \\
\hline
\end{tabular}

* Median (IQ: 25-75). ${ }^{* *}$ Mean \pm SD. ${ }^{* * *}$ P-value $<0.05$

status. After adjustment for confounders, adjusted mean difference of serum 25-OH-D between these 2 areas, with different ground level of UVB, was statistically significant. Living in more polluted areas i.e. east of Tehran significantly increases the probability of vitamin D insufficiency and deficiency.

High levels of atmospheric pollutions can reduce ground levels of UVB significantly $[6,9,16]$. Our results also show that these polluted areas reduce ground level of UVB. Thus, living in a polluted city can be one of the main reasons of vitamin D deficiency [17]. In this study, we have found that after adjustment for known parameters that may be important determinants of vitamin $\mathrm{D}$ status i.e. age, BMI, daily dietary vitamin $\mathrm{D}, \mathrm{Ca}, \mathrm{Pi}$, protein, and the levels of sunlight exposure $[18,19]$, living in higher polluted area result in lower level of serum 25-OH-D in healthy housewives, aged 20-55 years. ANCOVA and binary logistic analyses showed that after adjustment for different plausible confounders, the only parameter that remains in the model was the city of

Table 2 Comparison of biochemical parameters between Tehranian and Ghazvinian groups.

\begin{tabular}{llll}
\hline & Tehran & Ghazvin & P-value \\
\hline 25-OH-D $(\mathrm{ng} / \mathrm{ml})$ & $11(8-14)$ & $15.5(8.5-26)$ & $<001$ \\
\hline PTH(Pg/ml) & $64(60-68)$ & $58(45-65)$ & $<001$ \\
\hline ALP $(\mathrm{u} / \mathrm{l})$ & $157.5(133-180)$ & $156.5(126-185)$ & 0.46 \\
\hline Calcium $(\mathrm{mg} / \mathrm{dl})$ & $9.43(9.10-9.80)$ & $9.67(9.10-10.10)$ & 0.001 \\
\hline Phosphate $(\mathrm{mg} / \mathrm{dl})$ & $3.6(3.3-4)$ & $3.5(3-4)$ & 0.15 \\
\hline
\end{tabular}

Median (IQ: 25-75) of data are presented. residence as a surrogate of air pollution. To best of our knowledge, there are only two studies that reported the association between air pollution and vitamin D status, one in infants and toddlers in India and one in postmenopausal women living in Belgian, recruited from subjects attending the rheumatology outpatient clinic $[9,10]$. Both studies revealed that residents of high levels of air pollution were at increased risk of developing vitamin D-deficiency. Here, we reported that that living in a polluted area plays a significant independent role in vitamin $\mathrm{D}$ deficiency in healthy ambulatory women, aged

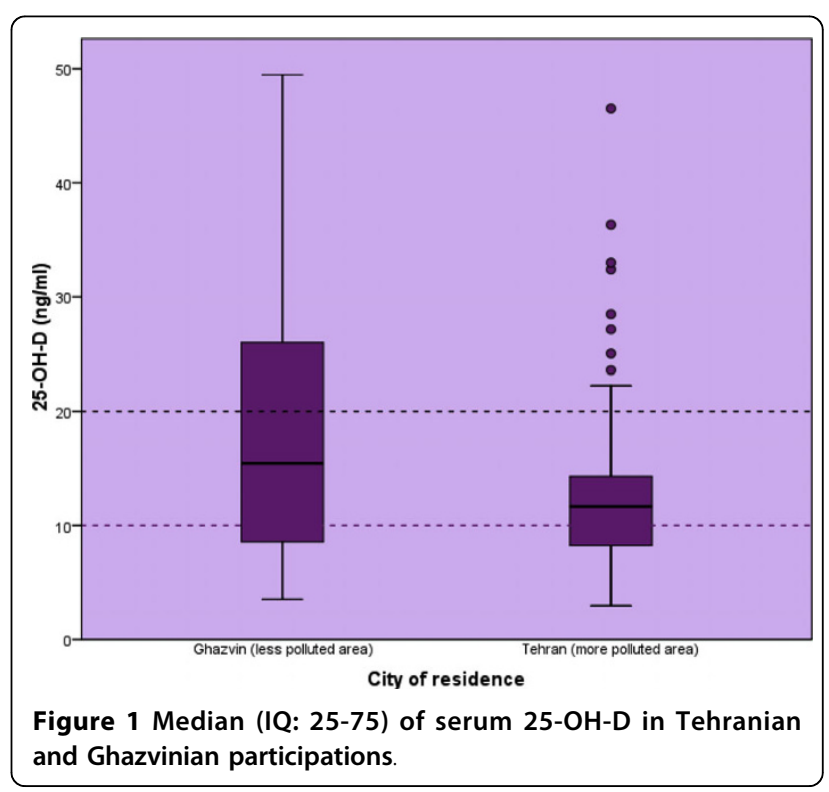


between 20 and 55 years. It should be restated that, aging significantly decrease the skin capacity of vitamin D synthesis in response to solar UVB [19]; thus the role of air pollution in elderly may be more prominent than the results that were seen in this study.

This study has limitations that are mainly due to problems related to our equipment. First, our hypothesis was that the lower ground levels of UVB in more polluted area are mainly due to atmospherics' pollutant aerosols but some other parameters may also contribute in it. Second, it was impossible for us to determine the main chemical particles that absorb and decrease UVB radiations. Third, because of limited number of centers that measured ground levels of UVB, we were unable to analysis the magnitude of UVB as a parameter and just defined the city of living as a surrogate of the ground level of UVB. Fourth, we did not calculate sun exposure index. But, it seems that due to the facts that Iranian women clothing styles have no significant variations and all of the women in this study were housewives, there is no significant differences between these two place sun exposure indexes. We defined simple questions for housing status, time spent outdoor, and the usage pattern of sunscreen instead of sun exposure index. Fifths, it was impossible to measure the blood levels of specific bone markers. Last but not least, it is important to mention that there is an increase in solar UVB doses from a difference in surface elevation above the sea level. The amount seems to be between $20 \%$ per $1000 \mathrm{~m}$ at the elevation of the two cities [20]. The elevation difference between the two cities is $640 \mathrm{~m}$, implying a difference of $12 \%$. This difference contributes, in part to differences in serum 25-OH-D levels (about 30\% percent of mentioned differences between Tehran and Ghazvin 25-OH$\mathrm{D}$ may be due to surface elevation differences). It would also affect the fraction of the populations below specified 25-OH-D levels. However, ground level of UVB was significantly higher in Ghazvin as compared with Tehran (mean (SE), 0.31(0.07) and 0.16(0.03) W/m 2 respectively, $\mathrm{P}$-value $=0.003)$. This means that at least $70 \%$ percent of serum vitamin D difference is due to air pollution. Despite these limitations, our study does have advantages over previous studies. Our strengths are: to define objectively the amount of air pollution, we measured the magnitude of UVB that reached the earth surface by the Haze meter instrument. In addition, daily information on dietary intake of vitamin $\mathrm{D}$ and duration of sun exposure, as two main determinant of vitamin D storage, were also considered. Besides these advantages, we recruited our samples from participants of a large population based study in Tehran and from public health centers in Ghazvin.

\section{Conclusion}

The question addressed by this study was whether air pollution affects the blood level of 25-OH-D in healthy women. We found that the place of living, as a surrogate of air pollution, has a significant influence on vitamin D status. Hence, controlling air pollution levels will promote the body vitamin $\mathrm{D}$ status.

\section{Acknowledgements}

We would like to thank the staff and participants in the TLGS study for their important contribution. We nearby acknowledge Mrs. Nilufar Shiva for her assistance in manuscript preparation and language editing.

\section{Author details}

${ }^{1}$ Obesity Research Center, Research Institute for Endocrine Sciences, Shahid Beheshti University of Medical Sciences, P.O. Box 193-4763, Tehran, Iran.

${ }^{2}$ Ghazvin Metabolic Research Center, Ghazvin University of Medical Science, Ghazvin, Iran. ${ }^{3}$ Endocrine Research Center, Research Institute for Endocrine Sciences, Shahid Beheshti University of Medical Sciences, P.O. Box 193-4763, Tehran, Iran. ${ }^{4}$ Ghazvin University of Medical Science, Ghazvin, Iran.

\section{Authors' contributions}

FH participated in the conception and design of the study, coordination and its final approval. SHP participated in its design. MH performed the statistical analysis and drafted the manuscript. NM helped in design and statistical analyses of the study. SA and FA revised the manuscript for important intellectual content. All authors read and approved the final manuscript.

\section{Competing interests}

The authors declare that they have no competing interests.

Received: 18 May 2010 Accepted: 29 August 2010

Published: 29 August 2010

\section{References}

1. Glerup H, Mikkelsen K, Poulsen L, Hass E, Overbeck S, Thomsen J, Charles P, Eriksen EF: Commonly recommended daily intake of vitamin $D$ is not sufficient if sunlight exposure is limited. J Intern Med 2000, 247(2):260-8.

2. Chen TC, Chimeh F, Lu Z, Mathieu J, Person KS, Zhang A, Kohn N, Martinello S, Berkowitz R, Holick MF: Factors that influence the cutaneous synthesis and dietary sources of vitamin D. Arch Biochem Biophys 2007, 460(2):213-7.

3. Brustad $M$, Alsaker $E$, Engelsen $O$, Aksnes L, Lund E: Vitamin D status of middle-aged women at 65-71 degrees $\mathrm{N}$ in relation to dietary intake and exposure to ultraviolet radiation. Public Health Nutr 2004, 7(2):327-35.

4. Cranney A, Horsley T, O'Donnell S, Weiler H, Puil L, Ooi D, Atkinson S, Ward L, Moher D, Hanley D, Fang M, Yazdi F, Garritty C, Sampson M, Barrowman N, Tsertsvadze A, Mamaladze V: Effectiveness and safety of vitamin D in relation to bone health. Evid Rep Technol Assess (Full Rep) 2007, 158:1-235.

5. Allali F, El Aichaoui S, Saoud B, Maaroufi H, Abouqal R, Hajjaj-Hassouni N: The impact of clothing style on bone mineral density among post menopausal women in Morocco: a case-control study. BMC Public Health 2006, 6:135.

6. Barnard WF, Saxena VK, Wenny BN, DeLuisi JJ: Daily surface UV exposure and its relationship to surface pollutant measurements. J Air Waste Manag Assoc 2003, 53(2):237-45.

7. Calbó J, Pagès D, González J-A: Empirical studies of cloud effects on UV radiation: A review. Rev Geophys 2005, 43:RG2002.

8. Allali F, El Aichaoui S, Khazani H, Benyahia B, Saoud B, El Kabbaj S, Bahiri R, Abouqal R, Hajjaj-Hassouni N: High prevalence of hypovitaminosis D in Morocco: relationship to lifestyle, physical performance, bone markers, and bone mineral density. Semin Arthritis Rheum 2009, 38(6):444-51.

9. Agarwal KS, Mughal MZ, Upadhyay P, Berry JL, Mawer EB, Puliyel JM: The impact of atmospheric pollution on vitamin $D$ status of infants and toddlers in Delhi, India. Arch Dis Child 2002, 87(2):111-3. 
10. Manicourt D-H, Devogelaer J-P: Urban Tropospheric Ozone Increases the Prevalence of Vitamin D Deficiency among Belgian Postmenopausal Women with Outdoor Activities during Summer. The Journal of Clinical Endocrinology \& Metabolism 2008, 93(10):3893-3899.

11. Azizi F, Rahmani M, Emami H, Madjid M: Tehran Lipid and Glucose Study. CVD Prevention 2000, 3:242-247.

12. Mirmiran $P$, Esfahani FH, Mehrabi $Y$, Hedayati M, Azizi F: Reliability and relative validity of an FFQ for nutrients in the Tehran lipid and glucose study. Public Health Nutr 2010, 13(5):654-62.

13. Azar M, Sarkisian E: Food composition table of Iran. Tehran: National Nutrition and Food Research Institue, Shahid Behershti University 1980.

14. Food Composition Table (FCT): food and nutrition information center, United State Department of Agriculture (USDA). [http://www.nal.usda. gov/fnic/foodcomp].

15. Malabanan A, Veronikis IE, Holick MF: Redefining vitamin D insufficiency. Lancet 1998, 351(9105):805-6.

16. Bach W: Solar irradiation and atmospheric pollution. Theoretical and Applied Climatology 2005, 21(1):67-75.

17. Holick M: Environmental factors that influence the cutaneous production of vitamin D. Am J Clin Nutr 1995, 61(3):638S-645S.

18. Vilarrasa N, Maravall J, Estepa A, Sánchez R, Masdevall C, Navarro MA, Alía P, Soler J, Gómez JM: Low 25-hydroxyvitamin D concentrations in obese women: their clinical significance and relationship with anthropometric and body composition variables. J Endocrinol Invest 2007, 30(8):653-8.

19. MacLaughlin J, Holick MF: Aging decreases the capacity of human skin to produce vitamin D3. J Clin Invest 1985, 76(4):1536-8.

20. Blumthaler M, Webb AR, Seckmeyer G, Bais AF, Huber M, Mayer B: Simultaneous spectroradiometry: A study of solar UV irradiance at two altitudes. Geophys Res Lett 1994, 21(25):2805-2808.

\section{Pre-publication history}

The pre-publication history for this paper can be accessed here: http://www.biomedcentral.com/1471-2458/10/519/prepub

doi:10.1186/1471-2458-10-519

Cite this article as: Hosseinpanah et al:: The effects of air pollution on vitamin $\mathrm{D}$ status in healthy women: A cross sectional study. BMC Public Health 2010 10:519.

\section{Submit your next manuscript to BioMed Central and take full advantage of:}

- Convenient online submission

- Thorough peer review

- No space constraints or color figure charges

- Immediate publication on acceptance

- Inclusion in PubMed, CAS, Scopus and Google Scholar

- Research which is freely available for redistribution 